\title{
Thermal maturity structures in an accretionary wedge by a numerical simulation
}

\author{
Ayumu Miyakawa ${ }^{1 *}$ (D, Masataka Kinoshita², Yohei Hamada and Makoto Otsubo
}

\begin{abstract}
This study investigates the thermal maturity structure of the accretionary wedge along with the thermal history of sediments during wedge formation using a numerical simulation. The thermal maturity, which is described in terms of vitrinite reflectance, is determined using the temperature and duration of exposure based on the particle trajectories within the accretionary wedge. This study revealed the variability in the thermal maturity even though sediments are observed to originate at an identical initial depth and thermal conditions. We propose two endmember pathways of sediment movement in the accretionary wedge during wedge growth: a shallow, low thermal maturity pathway and a deep, high thermal maturity pathway. These shallow path sediments, which move into the shallow portion of the wedge during wedge growth through accretion, rarely experience high temperatures; therefore, their thermal maturity is low. However, the sediments subducted in the deep portion of the wedge experience high temperatures and obtain high thermal maturity as a function of the deep high thermal maturity pathway. Simultaneously, a geological deformation event, such as faulting, defines the steps of thermal maturity. The small step of thermal maturity is formed by the frontal thrusting and can be preserved as a function of the shallow low thermal maturity pathway. However, the step is overprinted and is observed to disappear through the deep high thermal maturity pathway. The large step of thermal maturity is formed by long-term displacement along an out-of-sequence thrust (OOST) in the deep portion of the wedge.
\end{abstract}

Keywords: Accretionary wedge, Thermal maturity structure, Vitrinite reflectance, Out-of-sequence thrust, Numerical simulation

\section{Introduction}

Previous studies have depicted that the relative duration of peak heating within any accretionary wedge, especially during specific stages of deformation, can be ascertained by determining whether any discordance exists between megascopic structural geometries and paleothermal gradients. Thermal history (e.g., peak heating and its duration) is recorded in an organic material in the form of thermal maturity. The observations of these recorded thermal maturities and geological structures (e.g., intrusion and fault) have promoted a better understanding about the formation of the geological structures and the associated igneous activity (Underwood et al. 1992) as

\footnotetext{
* Correspondence: miyakawa-a@aist.go.jp

${ }^{1}$ Geological Survey of Japan, AIST, AIST Tsukuba Central 7, Higashi-1-1-1,

Tsukuba, Ibaraki Pref. 305-8567, Japan

Full list of author information is available at the end of the article
}

well as about the duration of thrusting (e.g., Sakaguchi 1996; Yamamoto et al. 2017). In order to represent these observations, various conceptual models have been proposed to interpret the relation between the recorded thermal maturities and geological structures (e.g., Underwood et al. 1993). The temporal development of thermal maturity and their relationships to the associated structures in accretionary wedges have been investigated to date (Barr and Dahlen 1989; Barr et al. 1991; Beyssac et al. 2007; Chen et al. 2017).

The difficulty that is encountered while defining the temporal development of thermal maturity and the associated structures originates from the fact that thermal maturity represents an integration of the exposed temperature and its duration during structural deformation. The thermal maturity recorded in vitrinite reflectance or in the Raman spectrum of carbonaceous 
materials (e.g., Beyssac et al. 2007; Jehlička et al. 2003; Sakaguchi 1996; Sweeney and Burnham 1990; Yamamoto et al. 2017), which are most frequently used as preservation indices of thermal history, is the integration of the entire history of the material (c.a., temperature and exposed time). Therefore, these indices can reveal the thermal history either as a function of the heating temperature or as a function of the duration. Thus, the unique trajectory of the sediments cannot be inferred by only using the observed thermal maturity indices because of the tradeoff between the exposed temperature and its duration.

In this study, the trajectory of the sediments and their thermal histories during wedge formation were examined using a numerical simulation. Previous studies have investigated the trajectory of particles in the wedges (e.g., Willett et al. 1993; Beaumont et al. 1999; Konstantinovskaia and Malavieille 2005; Stockmal et al. 2007; Mulugeta and Koyi 1992; Naylor and Sinclair 2007; Wenk and Huhn 2013). Herein, we obtained the trajectory of the particles using the distinct element method (DEM) (Cundall and Strack 1979). The temperature in the accretionary wedge was also calculated in order to evaluate the relation between the trajectory of the sediments and the thermal maturity. This approach can provide a spatiotemporal framework of the deformation and thermal maturity within the accretionary wedge. The results are going to be used to compare to natural systems to understand the thermal evolution across a wedge. Additionally, the established framework will promote understanding of the relation between thermal history as the thermal maturity and the associated structures in natural accretionary wedges.

\section{Methods/Experimental \\ Overview of the simulation}

The structure and thermal maturity are modeled by combining the numerical simulation that reproduces the geological and thermal structures in the accretionary wedge. The DEM geodynamic simulation can reproduce the evolution of the geological structure of the accretionary wedge. The thermal structure, on the other hand, was reconstructed using the observed thermal condition in the natural accretionary wedge. The particle tracks that are observed during the simulation of DEM imitate the tracks of the sediments in the accretionary wedge, and the simulated DEM particles that are traveling within the wedge detect the temperatures that are derived from the thermal structure. The thermal history of each particle can, therefore, be obtained. The vitrinite reflectance was used to represent the index of the thermal maturity that originated from the integration of the temperature and its duration.

\section{Reconstruction of the accretionary wedge using the DEM} method

We employed the DEM geodynamic modeling method to reconstruct the geological structure of the accretionary wedge. Several studies have reconstructed accretionary wedges using the DEM method (e.g., Morgan 2015; Burbidge and Braun 2002; Naylor and Sinclair 2007; Wenk and Huhn 2013; Yamada et al. 2006; Yamada et al. 2014; Miyakawa et al. 2016). The modeling process in this study follows the method given by Miyakawa et al. (2010) in which an accretionary wedge containing an out-of-sequence thrust (OOST) was reconstructed by increasing the basal friction in the model. OOSTs represent large displacements in the wedge, and several geological surveys found remarkable gaps in thermal maturity across OOSTs (e.g., Yamamoto et al. 2017). Consequently, it is expected that the numerical simulation will show remarkable variations in the thermal maturity structure across the OOST.

We used the model to reproduce the evolution of the accretionary wedge based on both the input of the sediments to the trench and the deforming sediments that are the basis of the body of the accretionary wedge. The initial condition of the model represents the coherent sediments on the oceanic plate (Fig. 1). The thickness of the sediments is set to $1000 \mathrm{~m}$. We employed two sets of particle parameters while performing a simulation of DEM (Table 1). The upper part of the sediment comprised strong particles (particle A) that represent sediments, whereas the lower part comprised a thin layer $(100 \mathrm{~m})$ of weak particles (particle B) that represent a weak layer of the décollement. The radii of the particles are diverse: $12-30 \mathrm{~m}$ for particle A and $6-10 \mathrm{~m}$ for particle $\mathrm{B}$. We did not consider interparticle bonding in our simulation. By setting weak particles, we reproduced the décollement zone, which has a thickness of several particles. Rigid walls confine the model boundaries, and the friction between the side walls and the particles is the same as the interparticle friction in particle A. A moving wall compresses the sediments to duplicate the accretion process. The displacement rate was observed to be small enough to approximate the deformation as quasi-static and was, therefore, set to be $0.009 \mathrm{~m}$ during each calculation cycle. The over a period of calculation cycle is explained in the next section. A basal slit $(60 \mathrm{~m}$ in height; observe Fig. 1) was used to generate a detachment horizon within the thin bottom décollement layer.

In this study, the OOST within an accretionary wedge was formed by increasing the basal strength of the model (Miyakawa et al. 2010). The increase in the basal strength was intended to simulate the varying pore pressure distribution (Bangs et al. 2004) and/or material properties (Hyndman and Wang 1993), which control the strength of the décollement. The pore pressure 


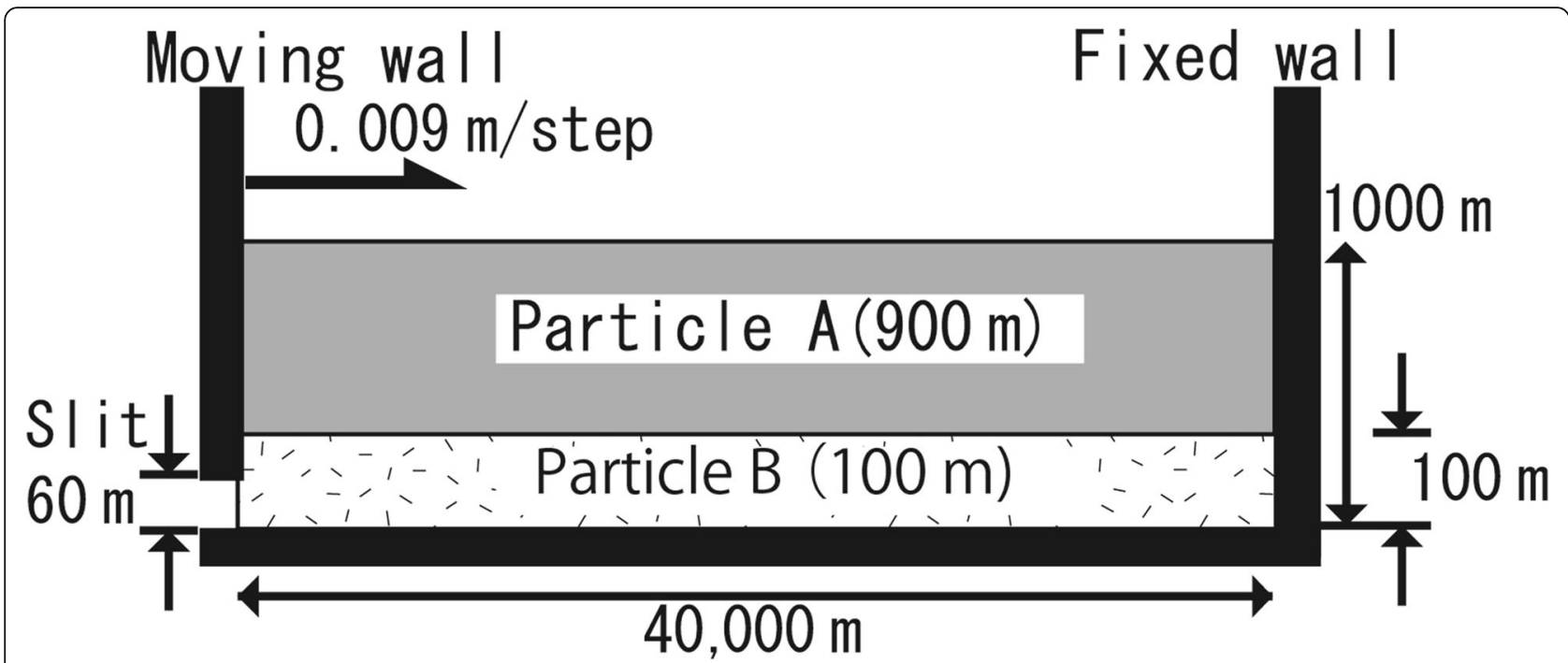

Fig. 1 Setup to perform the numerical simulations. The upper layer (100-1000 m) comprises particle A, whereas the bottom layer (0-100 m) comprises particle B. The left side wall pushes the particles to the right side at a small rate of displacement $(0.009 \mathrm{~m}$ for each calculation time step). The moving wall has a slit $(0-60 \mathrm{~m})$ to produce a detachment (décollement) within the bottom layer. The shear drag factor of particle B increases from the left-hand side to the right-hand side in response to the displacement of the moving wall (modified after Miyakawa et al. 2010)

distribution and material properties were affected by the alterations in various parameters such as the temperature, overburden thickness, porosity, and development of faults and fractures that act as fluid conduits. It is difficult to consider these parameters directly while performing the DEM simulation. Therefore, we increased the basal strength of the particles in the thin bottom layer. We gradually increased the interparticle friction of the particles in the thin bottom layer from left to right. The rate of increase was a function of the amount of shortening (see Miyakawa et al. 2010 for details). The function maintained a constant distance between the trench position and the strength increase zone. The functional increase in the strength of the particles models the loss of pore pressure and the hardening of the material along the décollement as a function of the evolution of the accretionary wedge. The simulation was performed using the two-dimensional particle flow code (PFC2D) software (ITASCA Corp., Minneapolis, USA).

Timescale conversion from the DEM model to the thermal model

The definition of the timescale is critical to bridge the gap between the deformation rate during the simulation of DEM and the heating rate that was obtained from the

Table 1 Parameters of the particles used in the DEM simulation

\begin{tabular}{lll}
\hline & Particle A & Particle B \\
\hline Radius $(\mathrm{m})$ & $12-30$ & $6-10$ \\
Density $\left(\mathrm{kg} / \mathrm{m}^{3}\right)$ & 2650 & 2650 \\
Friction coefficient between particles & 30 & $0.5-30$ \\
\hline
\end{tabular}

thermal structure. The calculation cost of the DEM method was observed to be so high that we were not able to calculate the deformation during the simulation of DEM over the natural geological timescale (i.e., thousands or millions of years). The timescale used for the DEM simulation, therefore, was set to satisfy the quasi-static deformation conditions to imitate the long-term geological deformation. Consequently, the timescale of the calculation step during the DEM simulation cannot be directly converted to the timescale of the thermal model. To solve this problem, we introduced a normalized timescale based on the displacement of the moving wall, which controls the deformation rate.

The shortening rate that was observed in the natural subduction zone and the shortening rate in this model were set to be equal in the normalized timescale by the displacement of the moving wall. The wedge deformations in the natural geological structures and the numerical simulation were derived from the shortening of the plate subduction zone and the moving wall, respectively. The shortening rate in the plate subduction zone was $4 \mathrm{~cm} /$ year in the Nankai Trough, southwest Japan (Seno et al. 1993), whereas the shortening rate of the moving wall was $0.9 \mathrm{~cm} / \mathrm{step}$ in our simulation timestep. Therefore, to calibrate the shortening rate in this model with that observed in nature, the timescale should be maintained to be 0.225 years/step. Hereafter, the heating duration in the DEM model is maintained to be 0.225 years/step. This normalized timescale reconciles the deformation rate during the simulation of DEM and the heating duration from the thermal model by imitating the deformation rate and heating duration that are observed in nature. 


\section{Thermal model}

The thermal structure was reconstructed with reference to the thermal condition of the natural accretionary wedge. The heat-flow data that was collected along the individual marine transects depict that the geothermal gradients considerably decrease in magnitude as a function of the arcward distance of the subduction front and that a thermal structure developed because of the combined effects of the cooling of the slab as it subducted and the thickening of the depth of the deformed sediments in the overlying accretionary wedge (Underwood et al. 1993). For example, Harris et al. (2013) noted that the thermal gradient at the location of the incoming sediments was $70-90^{\circ} \mathrm{C} / \mathrm{km}$ and that the thermal gradient at the wedge edge was $40-50^{\circ} \mathrm{C} / \mathrm{km}$ in the Kumano area of the Nankai Trough, southwest Japan. In this study, therefore, a high thermal gradient was set at the location of the incoming sediments, whereas a low thermal gradient was set at the wedge. The trench denotes the boundary between the incoming sediments and the wedge. The position of the trench, however, changes each time a new frontal thrust forms; therefore, the thermal gradient may not follow the trend very carefully. Therefore, we functionalized the position of the trench by interpolating the tip of the frontal thrust because the position of the trench intermittently migrates rightward (i.e., seaward), which results in the formation of new frontal thrusts (Miyakawa et al. 2010). The thermal gradient at the location of the incoming sediments was $90^{\circ} \mathrm{C} / \mathrm{km}$ to the right side (i.e., seaward) of the trench. The thermal gradient at the wedge was $50{ }^{\circ} \mathrm{C} / \mathrm{km}$ to the left side (i.e., landward) of the final wedge after performing $22,500 \mathrm{~m}$ of shortening (Additional file 1: Table S1). The thermal gradient between the incoming sediments and the wedge was interpolated linearly connecting two end-member gradients (Fig. 2, Additional file 1: Figure S2).

The temperature of each particle was calculated according to its buried depth from the surface and thermal gradient at that point. We calculated and updated the temperature of the particles after every 10,000 timesteps (i.e., 2250 years). The particles were preheated to the initial temperatures that were recorded at the locations of the incoming sediments for 1,650,000 timesteps (i.e., 371,250 years) to duplicate the heating process that occurred after sedimentation and to prevent rapid spikes in the temperature of the numerical simulation.

The thermal maturity of each particle was given as the vitrinite reflectance that was reproducing profiles observed in natural accretionary wedges. Sweeney and Burnham (1990) constructed a kinetic model by employing a series of first-order kinetics that describes parallel chemical reactions, which are associated with the progress of vitrinite thermal maturation $\left(\right.$ Easy\% $\left.R_{o}\right)$. Suzuki et al. (1993) proposed an improved kinetic model based on single activation energy, which is more suitable to perform numerical treatment (SIMPLE- $\left.R_{\mathrm{o}}\right)$. In their model, the vitrinite reflectance, $R_{o}$, is expressed as a function of the fraction of the reacted material, Fc, as follows:

$$
R_{o}=\exp \left[\ln \left(\mathrm{Ro}_{0}\right)+3.7 \mathrm{Fc}\right]
$$

where $\mathrm{Ro}_{0}$ is the initial reflectance of vitrinite. Fc can be written as follows:

$$
\mathrm{Fc}=0.85-0.85 \exp [-A \exp (-E \Delta t / \mathrm{RT})],
$$

where $A$ is a frequency factor $(1.0 \times 1013 / \mathrm{s}), R$ is a gas constant, $\Delta t$ is duration of calculation interval, and $E$ is the activation energy that can be represented as:

$$
E=40.7 \ln (\mathrm{Ro})+227[\mathrm{~kJ} / \mathrm{mol}] \text {. }
$$

\section{Results}

\section{Formation of an accretionary wedge and fault activity}

The formation process of an accretionary wedge, including a fault, was reconstructed through numerical simulation using the DEM (Fig. 3 and Additional file 2: Movie S1). The incoming sediments were offscraped by the moving wall and were deformed, thus forming reverse faults. The thickness of the wedge increased in parallel with the increased shortening.

The activity of the fault varied throughout the simulation. The active faults were distinguished by the discontinuity between the displacements of the particles while performing $90 \mathrm{~m}$ of shortening (Fig. 3). The most active fault was the frontal thrust, which partitioned the incoming sediment and the accretionary wedge at the trench. The activity of the frontal thrust reduced when a new frontal thrust was formed further toward the sea (i.e., the right side). The faults in the accretionary wedge were reactivated at times during the shortening process although the displacement was smaller than that observed for the active frontal thrust. The most remarkable reactivated fault was the OOST. The motion along the OOST continued for a long period of time, and, consequently, the amount of displacement along the OOST was observed to be large.

\section{Particle tracks and their depth and thermal history}

The trajectories of particles are observed to vary as a function of their burial depth and the position relative to active thrust fault (e.g., Konstantinovskaia and Malavieille 2005. Consequently, the thermal history of each particle is observed to be different. The trajectories of particles can be traced by tracking the position of the target particles at every step. We set four tracking particles in the model (Fig. 3). The initial 


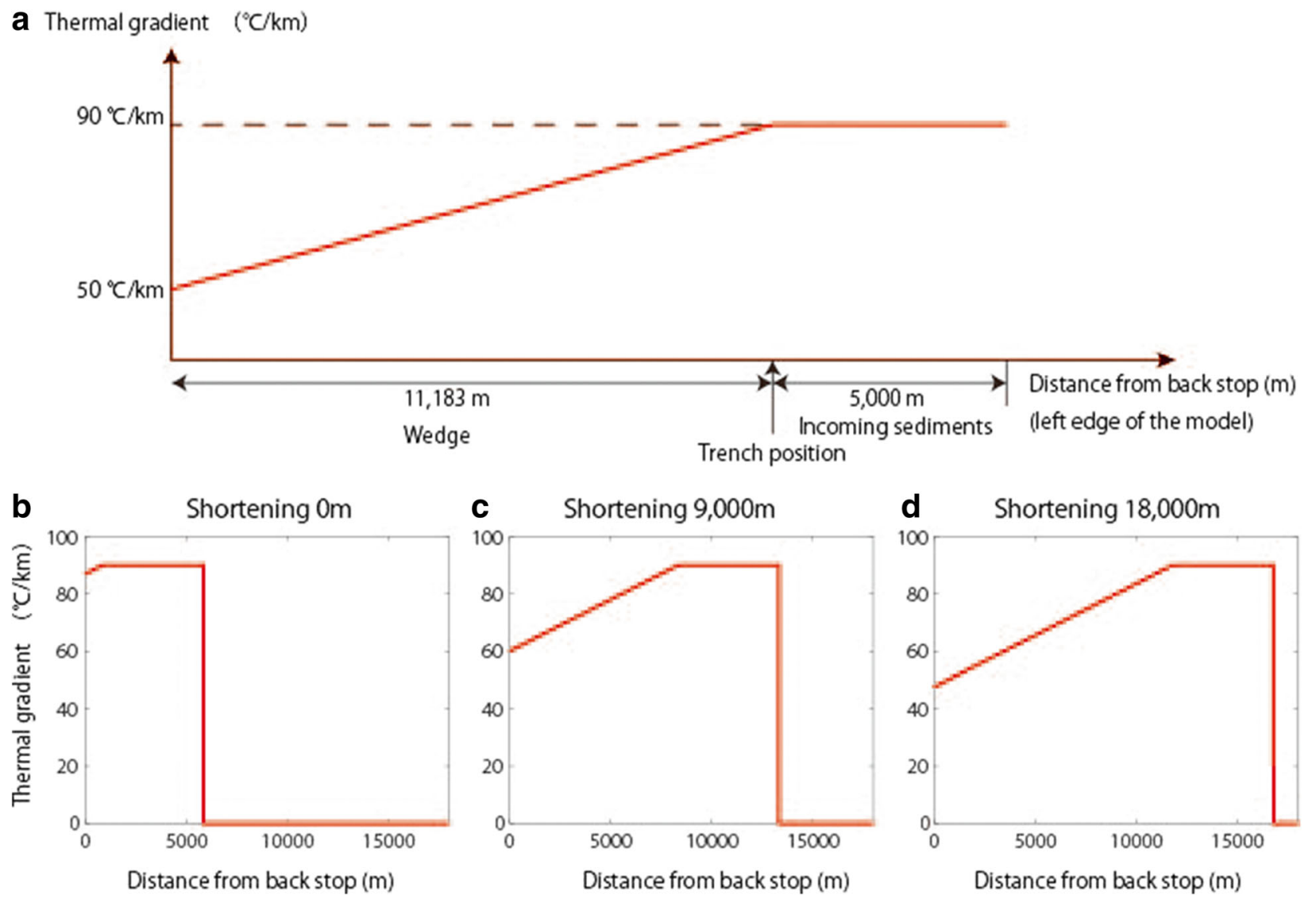

Fig. 2 The thermal gradient models for the calculation of the temperature of each particle. The horizontal axis depicts the distance from the left side wall (c.a., moving backstop), whereas the vertical axis depicts the thermal gradient. The thermal gradient is linearly interpolated from the input sediments at $90^{\circ} \mathrm{C} / \mathrm{km}$ to the landward end at $50^{\circ} \mathrm{C} / \mathrm{km}$ in the final condition. The final thermal gradient model after $22,500 \mathrm{~m}$ of shortening (a). The thermal gradient model for different amounts of shortening, i.e., for $0 \mathrm{~m}$ (c.a., initial condition) (b), $9000 \mathrm{~m}$ (c), and 18,000 m (d)

depths of these tracking particles in the incoming sediment were observed to be approximately the same (about $500 \mathrm{~m}$ ). Therefore, every trajectory overlapped until the sediment was accreted by the formation of the frontal thrust in the vicinity of the target particles. Once they were accreted into the wedge, the trajectories of the tracking particles diverged into different pathways. The difference between the pathways is reflected in the difference between the final burial depths of the tracking particles (Fig. 4). Consequently, the temperature of the particles and the $R_{o} \%$ values reflect the variability in the thermal history of the particles despite originating from an identical initial temperature condition.

The temperature and the $R_{o} \%$ of every particle were calculated according to the trajectory of each particle in the manner shown above. Finally, we obtained the temperature and vitrinite reflectance structures in the wedge (Fig. 5 and Additional file 3: Movie S2). The structure of the thermal maturity as elucidated by vitrinite reflectance $\left(R_{o} \%\right)$ was spatiotemporally discontinuous despite the continuous thermal structure (Fig. 5). The discontinuity of the thermal maturity, as observed using the vitrinite reflectance, was considerably evident along the frontal fault and the OOST. The step observed during the thermal maturity along the frontal thrust, especially at a particular depth, disappeared with the growth of the wedge. The most remarkable step was observed along the OOST.

The impacts of the order of the normalized timescale and the variation in the thermal gradient model are examined in Additional file 1: Figures S1, S2, and S3. The qualitative thermal structure and the thermal maturity structures are independent of the difference between the normalized timescale and the thermal gradient model, though the absolute values of temperature and thermal maturity have been changed.

\section{Profiles of the thermal maturity}

The spatial variation of the steps in thermal maturity is observed along both the horizontal and vertical profiles 


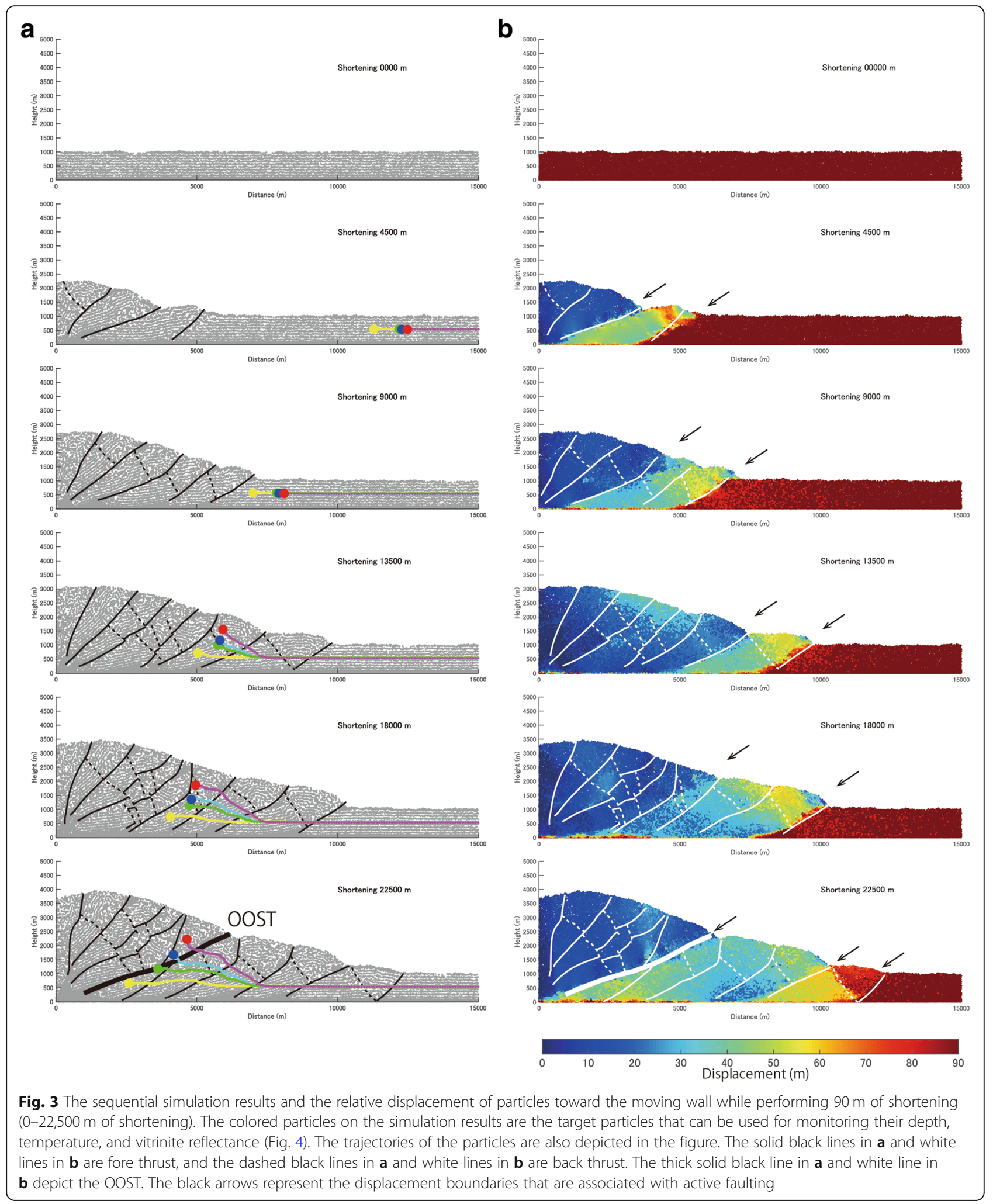

(Fig. 6). Generally, thermal maturity increases landward with increasing depth. This trend originated from the high temperature that was experienced and the resultant thickening of the wedge. The large steps in thermal maturity are concurrent with the fault development in both the horizontal and vertical profiles. 

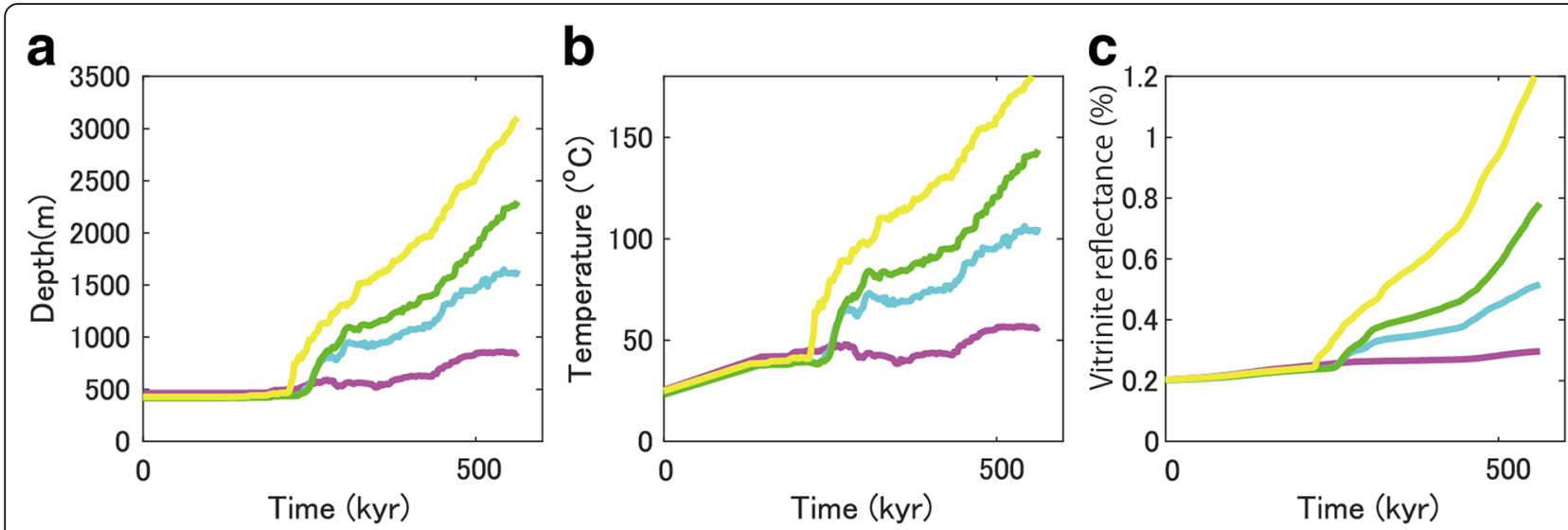

Fig. 4 The depth $(\mathbf{a})$, temperature $(\mathbf{b})$, and vitrinite reflectance $(\mathbf{c})$ vs. the time of the target particles. The colors of the lines correspond to the colors of the particle in Fig. 3

\section{Discussion}

\section{Comparison between the conceptual model and the natural accretionary wedge}

The relation between the recorded thermal maturities and the geological structures during the numerical simulation reproduces the conceptual model that is depicted in Underwood et al. (1993). Thermal maturity inversion, which is observed as a step in thermal maturity in our simulation, occurs in an accretionary wedge when the hanging wall strata are uplifted and thrusted over the less mature strata of a foot wall (Fig. 6B in Underwood et al. 1993). This type of thermal maturity inversion is observed in our numerical simulation, particularly across the frontal thrust and OOST (Fig. 6).

We compared the results of the numerical simulation and the natural accretionary wedge observations, which denote young and unmetamorphosed complexes in the Miura and Boso peninsulas of central Japan (Yamamoto 2006; Yamamoto et al. 2017). The Early Miocene and Late Miocene to Pliocene accretionary complexes that were exposed in this area are still observed to contain $30-50 \%$ of their initial porosity and low P-wave velocity structures (Yamamoto 2006). The observed maximum paleotemperatures of the Miura-Boso accretionary wedge ranges from 0 to $150{ }^{\circ} \mathrm{C}$ (Yamamoto et al. 2017). Higher maximum paleotemperatures are restricted to the western (c.a., landward) part of the Early Miocene Hota accretionary complex, which indicates a spatial difference in the slip upon OOST (Yamamoto et al. 2017). The range of the maximum paleotemperatures that were observed in the Miura-Boso accretionary wedge was consistent with that obtained from the numerical simulation (Fig. 5). Specific variations in the maximum paleotemperature, which cause an increase in the maximum paleotemperature toward the land, and the large steps across large OOSTs are also consistent with that observed during the numerical simulations. These results and observations lead to the conclusion that the thermal maturity in the numerical simulation is highly representative of the thermal maturity that occurs in the natural accretionary wedge. Our results also show that the existence and absence of steps in the thermal maturity observed in the natural accretionary wedge should be considered while examining the higher temperature overprints and the reactivation of the fault.

Thermal history of the sediments and the spatiotemporal evolution of the thermal maturity

The simulation results described the thermal history of the sediments and the spatiotemporal evolution of the thermal maturity structures that were associated with the wedge growth. The thermal history is controlled by the two components of subducting and faulting. The subducting and faulting associated with the wedge growth cause the overall maturity of the vitrinite, the formation of steps during thermal maturity, the banishment of the step, and the reformation of the step. Hence, this thermal maturity and its spatiotemporal evolution are associated with the stage of wedge growth.

\section{Incoming sediment}

The incoming sediments, which are pre-subducting sediments, are heated in a high thermal gradient on the oceanic plate. The deeper sediments depicted higher vitrinite reflectance $\left(R_{o} \%\right)$ than that observed in the shallower sediments due to the high thermal gradient that was observed in this stage. Hence, vitrinite reflectance is identical across sediments at similar depth. The maximum vitrinite reflectance that was encountered in the input sediments at depth was, however, lower than that observed in the deeper part of the inner wedge because the thicknesses of the input sediments were thinner $(\sim 1$ $\mathrm{km})$ than that of the wedge $(\sim 4 \mathrm{~km})$. 


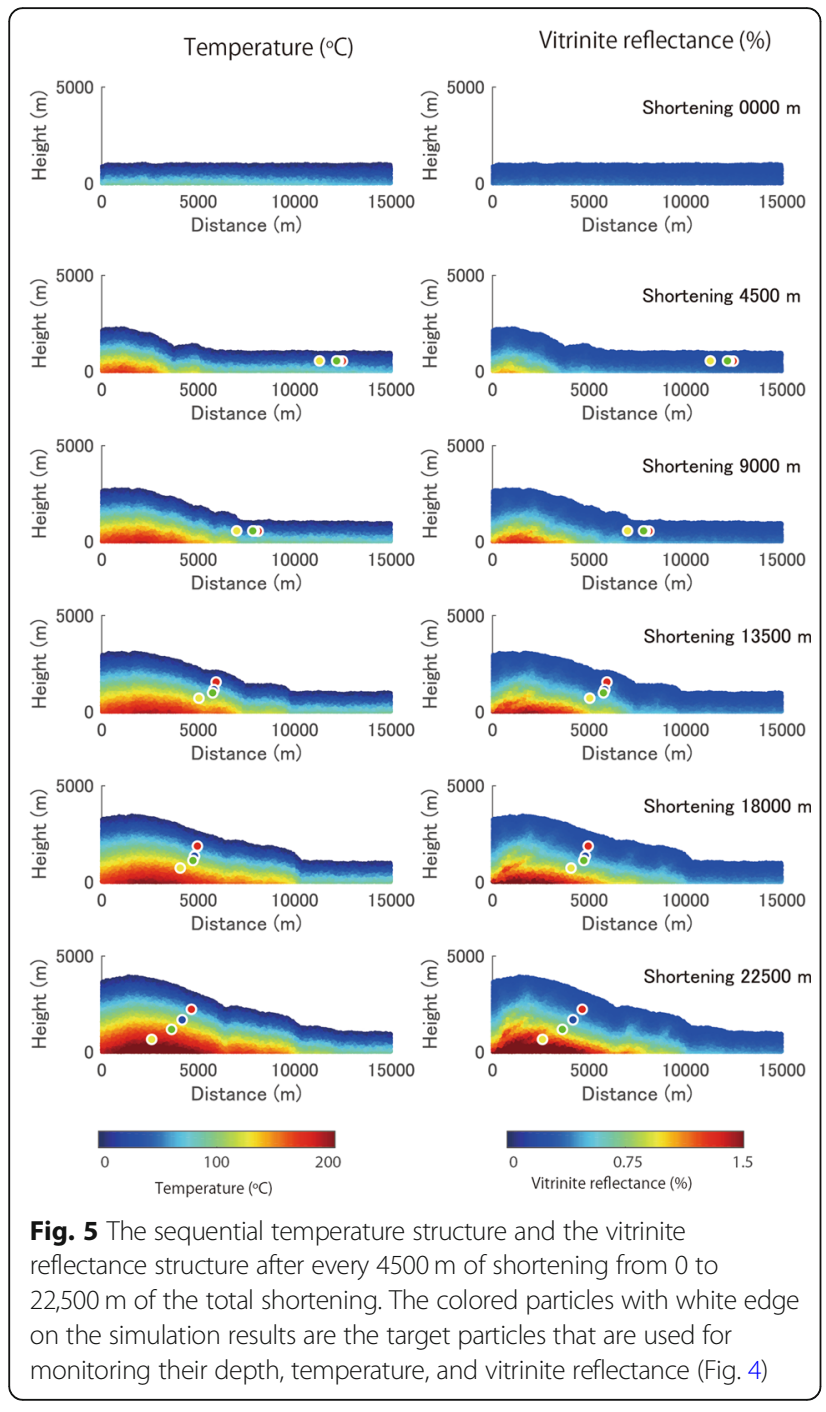

\section{Frontal thrust region}

The step in thermal maturity was formed in the frontal thrust region, where the incoming sediment was scraped off by the frontal thrust formation. The displacement along the frontal thrust shifted the horizontally layered thermal maturity structure. The thickness at the toe of the wedge was, however, still thinner than the thickness at the landward inner wedge. Hence, the vitrinite reflectance value and its step function along the frontal thrust were still small.

\section{Shallow part of the accretionary wedge}

The shallow portion of the accreted sediments did not subduct and remained at a shallow depth. These shallow sediments rarely experience high temperatures, and the vitrinite reflectance is rarely overprinted by the higher temperature. The shallow sediments, therefore, maintain the vitrinite reflectance
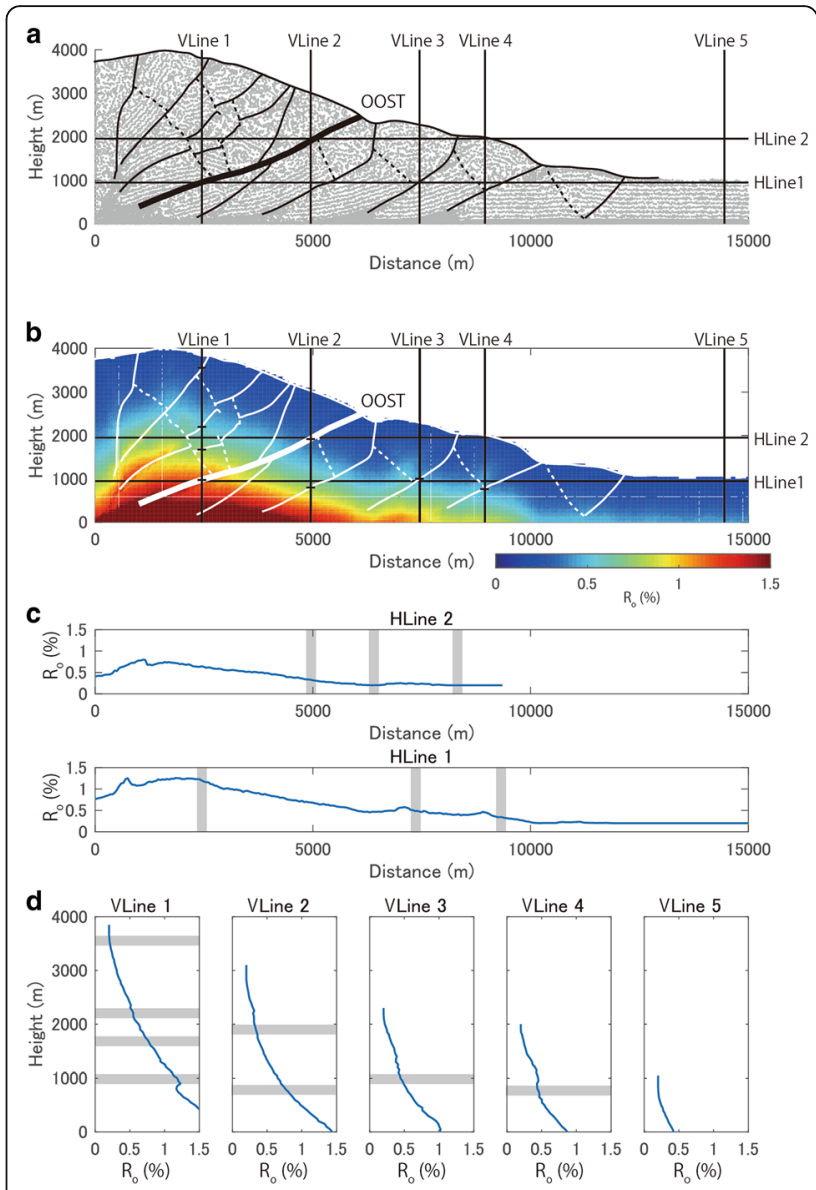

Fig. 6 The geological and the thermal maturity structure after 22,500 $\mathrm{m}$ of the total shortening. The geological structure (a). The thermal maturity structure as the vitrinite reflectance structure (b). The horizontal profiles of the vitrinite reflectance $(\mathbf{c})$. The vertical profiles of the vitrinite reflectance $(\mathbf{d})$. The position of the profile lines is displayed on the geological structure and the thermal maturity structure. The solid black lines in $\mathbf{a}$ and white lines in $\mathbf{b}$ are fore thrust, and the broken black lines in $\mathbf{a}$ and white lines in $\mathbf{b}$ are back thrust. The thick slid black line in $\mathbf{a}$ and white line in $\mathbf{b}$ depict the OOST. The gray shades in $\mathbf{c}$ and $\mathbf{d}$ depict position of the faults crossing the profile lines

of the incoming sediments and the step of the thermal maturity that was obtained by frontal thrusting. This preservation enables us to observe the low vitrinite reflectance value and the small steps during thermal maturity in the shallow part of the wedge. Recent ocean drilling activities revealed low-grade metamorphism and vitrinite reflectance along with small steps of thermal maturity at the shallow portion of the wedge in the Nankai Trough in the southwest part of Japan (Fukuchi et al. 2017).

\section{Deep part of the accretionary wedge}

The deep portion of the accreted sediments subduct and get deeper with the growth of the wedge. The sediments 
experience higher temperatures than those experienced by the incoming sediments and by the toe of the wedge. Consequently, the deep sediments depict high vitrinite reflectance values. While the present frontal thrust at the toe is active, the important point is that the paleofrontal thrust was already inactive at this stage. Therefore, the higher vitrinite reflectance overprints the existing thermal maturity structure, and the steps of thermal maturity disappear gradually, though thrust faults have steps (e.g., lower shaded zone in Fig. 6d). This absence of steps in the vitrinite reflectance along the faults is assumed to be caused by the overprint of the higher vitrinite reflectance that is associated with the subduction. In fact, faults without any steps in the vitrinite reflectance were observed in the natural wedge (e.g., Kitamura et al. 2005).

\section{Reactivation of the fault and OOST}

The steps in thermal maturity are recreated by the reactivation of the landward and inner wedge. The reactivation of the faults in the landward and inner wedge was clearly observed as a gap in displacement (black arrows in Fig. 3). This gap of displacement along the fault rebuilds the steps of the vitrinite reflectance profile (Fig. 6). The most remarkable reactivated fault in the inner wedge is the OOST. The large displacement along the OOST formed the large steps of the vitrinite reflectance. Similar large steps, across the OOST, have also been reported in natural accretionary wedges (e.g., Yamamoto et al. 2017) (Fig. 7).

\section{Summary of the spatiotemporal evolution of the thermal maturity}

Two end-members of paths of thermal maturity were revealed with the simulation: the deep and high thermal maturity pathway and the shallow and low thermal maturity pathway (Fig. 8). The thickness of the wedge increased with wedge growth, and the sediments that were subducting into the deeper part of the wedge experienced increasingly high temperatures and obtained high thermal maturity. However, the sediments in the shallow part of the wedge maintained low temperatures, and therefore, the thermal maturity also remained low.

The steps in thermal maturity are assumed to be caused due to the fault displacement (Fig. 8). The initial step of thermal maturity was formed because of the displacement of the frontal thrust. The step, however, disappears due to the overprinting of the high-grade vitrinite reflectance in the deep pathway even though the step is preserved in the shallow path. The steps in the high-level thermal maturity were formed during fault reactivation or the formation of OOST in the inner wedge.
The disappearance of the step and the overprinting of the high vitrinite reflectance are important features that may occur in a natural accretionary wedge (Fig. 8). A large fault which lacks a thermal maturity step has been reported although the large fault is assumed to be a seismogenic fault indicated by the presence of pseudotachylyte (Kitamura et al. 2005). One proposed interpretation is that the large fault was parallel to the isotherms. In subduction zones, the plate boundary décollement gently dips almost parallel to the isotherms (Underwood et al. 1989), which indicates that the displacement along the décollement does not cause a thermal contrast between the hanging wall and the foot wall sides. The lack of a thermal step across the Minami-Awa fault in southwest Japan was consistent with the expected thermal structure of the plate boundary décollement (Kitamura et al. 2005). However, our results suggest another explanation for the absence of steps of thermal maturity across the fault. Though a step in thermal maturity may have formed during the large fault displacement, which may have produced pseudotachylyte during its slip, the strata were subducted after the fault became inactive after which it experienced higher temperatures. At that time, both the hanging and foot wall strata obtained high-grade vitrinite reflectance, and the step of vitrinite reflectance disappeared. The high-grade vitrinite reflectance overprint may be caused not only due to subduction but also due to some other external factors such as an igneous activity (Sakaguchi 1996; Underwood et al. 1992).

\section{Limitations of assumptions and model simplifications}

The simplified assumptions in the model should be more realistic in future work. Our model does not take heat conduction into account, although we assume a constant thermal gradient at a given depth and a steady-state distribution in temperature. Therefore, our model will not be consistent with convective heat transport linked to faulting and fluid flow within the wedge. Consequently, steps in temperature across faults and heterogeneous variations in thermal gradients in the real system would not be reproduced in our model. The boundary condition of our model should also be improved to reproduce the complex natural conditions of accretionary wedges. For example, other studies suggest that an output of material (subducting sediments) through a type of "subduction channel" is responsible for major OOST faults in a wedge (e.g., Kukowski et al. 1994 and Gutscher et al. 1998). Several boundary conditions should be tested in future work, as our model is just one example of the formation of the OOST.

The deformational and thermal events were concurrent and affected each other in the natural environment. With syn-metamorphic faulting, the foot wall will be subjected to the effects of conductive heat transfer across the fault surface, and the thermal 
a

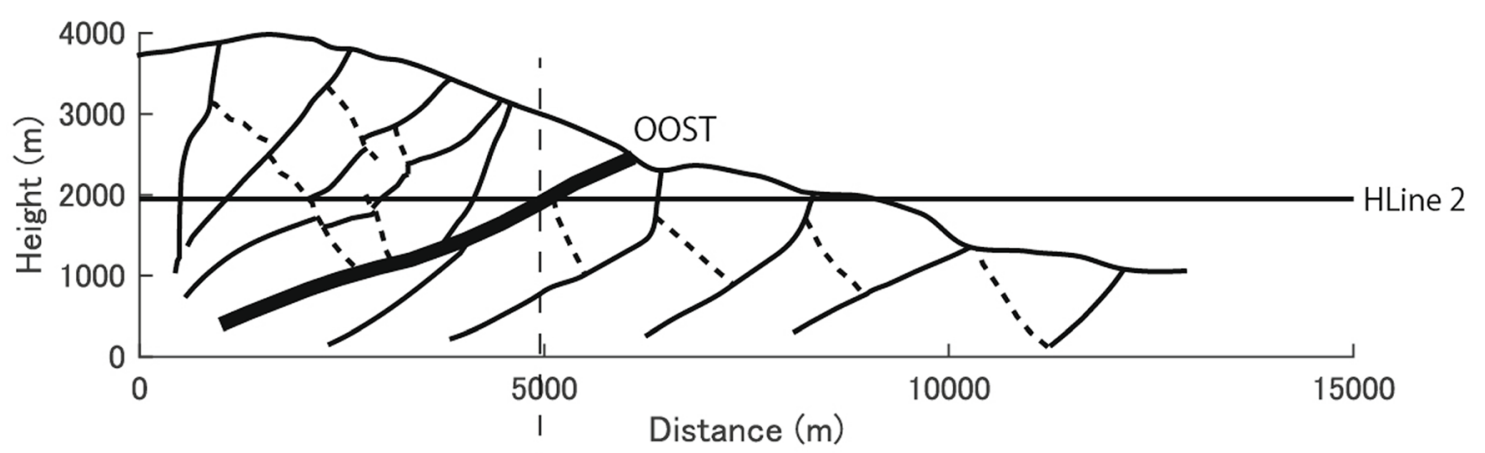

b

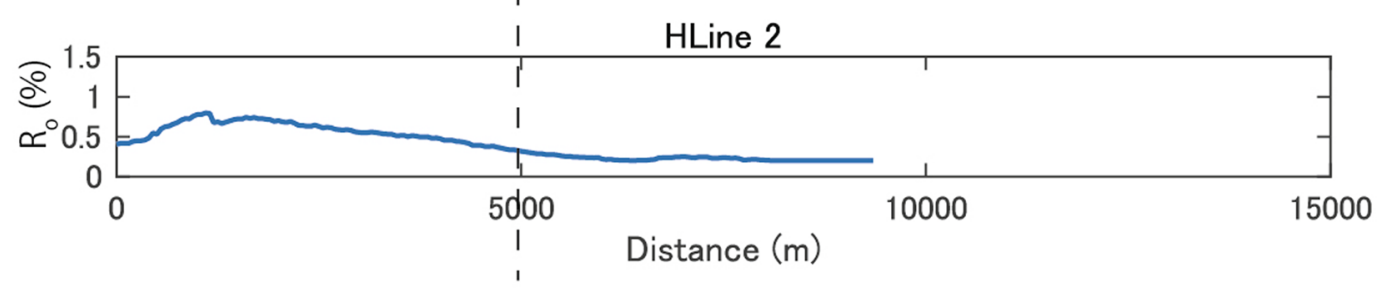

C

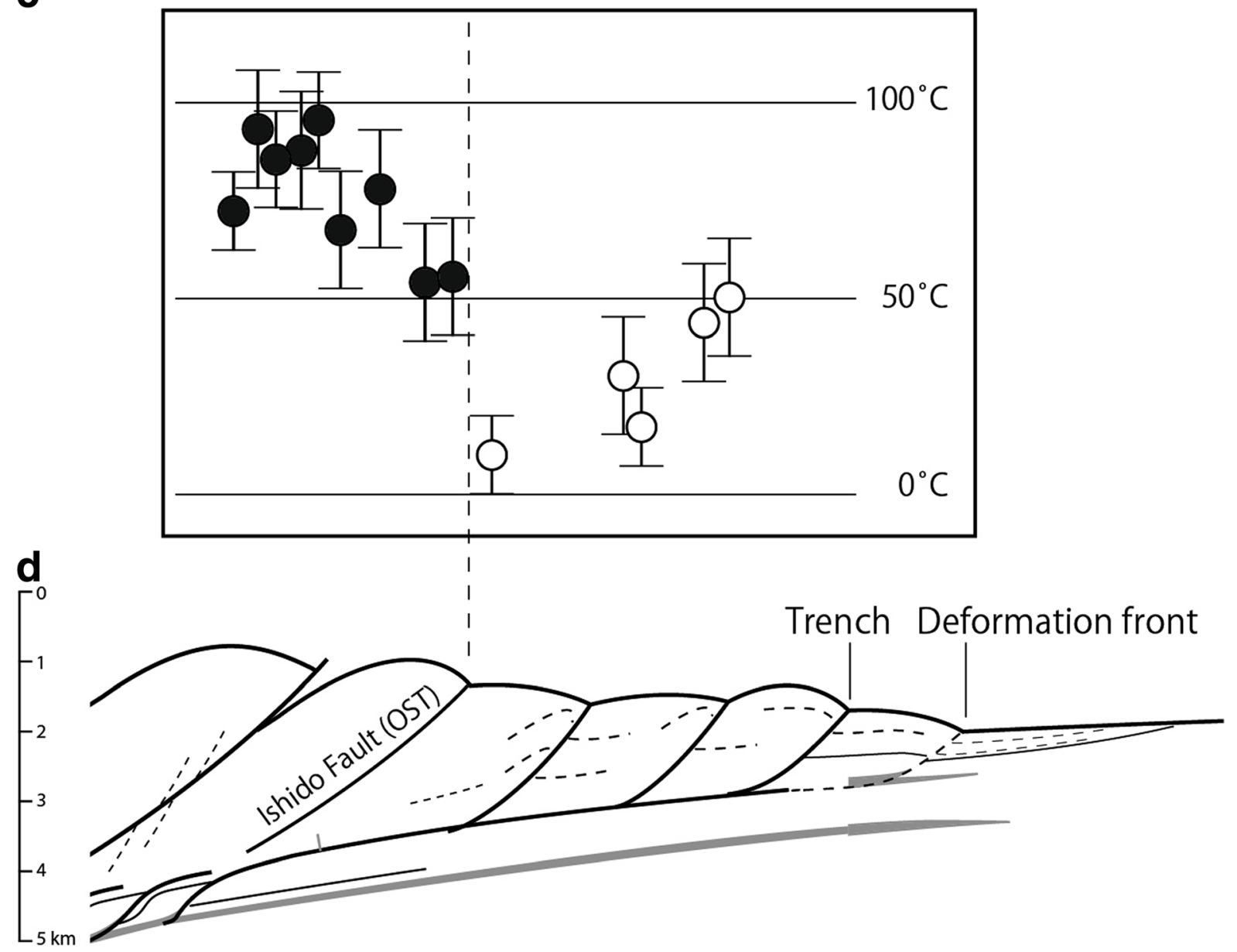

Fig. 7 A comparison of the numerical model and the natural accretionary wedge. The geological structure (a) and the horizontal profiles of the vitrinite reflectance (b) of the numerical simulation (Fig. 6). Schematic cross-section of the Miura-Boso subduction margin showing maximum paleo-temperatures deduced from the Boso Peninsula (c, d) (modified after Yamamoto et al. 2017) 


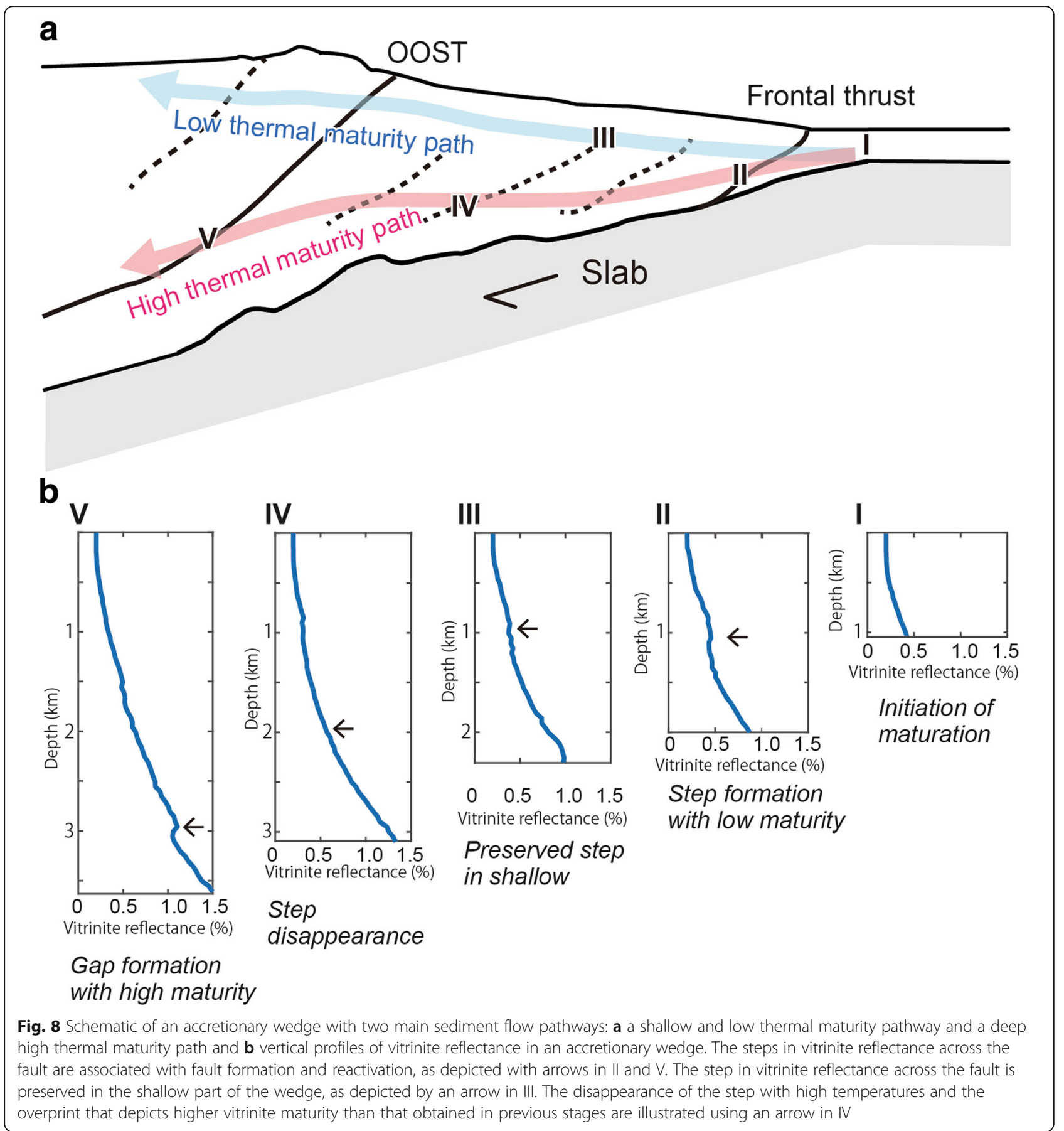

maturity indicators will be reset (Underwood et al. 1993). Therefore, thermomechanical simulation techniques (e.g., Gerya and Stöckhert 2006) may enable a considerably more detailed examination. The effect of thermal fluid flow or a local geological event, such as the encroachment of magmatic intrusions, which were not taken into account in our model, may also be important explanatory variables of the local thermal history.

\section{Conclusions}

We modeled a simple geological and thermal maturity structure by coupling a wedge deformation model and a thermal structure model. The results of the numerical simulation were observed to agree with the natural accretionary wedge observations. The simulation results described the thermal history of the sediments and the spatiotemporal evolution of the thermal maturity structures that were associated with the wedge 
growth. Two paths of thermal maturity are depicted: one is the deep and high thermal maturity pathway and the other is the shallow and low thermal maturity pathway. The subducting and faulting associated with the wedge growth control the overall maturity of the vitrinite, and the formation of steps, the decay of the step, and the reformation of the step. Our results depict that the existence and absence of steps of thermal maturity should be considered while examining the higher temperature overprint and the reactivation of the fault. The simplified assumptions in the model should be more realistic in future work.

\section{Additional files}

Additional file 1: Supporting information. Figure S1. Variation in the temperature structures and the thermal maturity structures as a function of the distribution of the vitrinite reflectance based on the difference of the normalized timescales of short $(0.0225$ year/step), moderate $(0.225$ year/step), and long (2.25 year/step) timescale models. Figure $\mathbf{S}$. Variation in the thermal gradient models (Table S1.). Table S1. Thermal gradient models. Figure S3. Variation of the temperature structures and the thermal maturity structures as a distribution of the vitrinite reflectance that was derived using different thermal gradient models: $\mathrm{HH}$, $\mathrm{HL}$, LH, and LL models. (DOCX $3942 \mathrm{~kb}$ )

Additional file 2: Movie S1. Evolution of the structure of the accretionary wedge and the distribution of the displacement of each particle (AVl $4329 \mathrm{~kb}$ )

Additional file 3: Movie S2. Evolution of the temperature and thermal structure within the wedge. (AVI $4780 \mathrm{~kb}$ )

\section{Abbreviations}

DEM: Distinct element method; OOST: Out-of-sequence thrust

\section{Acknowledgements}

We are grateful to S. Tonai (Kochi University), R. Fukuchi (JAMSTEC) and H. Hara (Geological survey of Japan). We also thank two anonymous reviewers for providing constructive reviews that greatly improved the manuscript.

\section{Funding}

A.M. was supported by JSPS KAKENHI Grant Number JP17H05321.

\section{Availability of data and materials}

The datasets in the current study are available from the corresponding author on request.

\section{Authors' contributions}

AM conducted the numerical simulation and designed the study. MK proposed the topic and investigated the thermal model. YH carried out the experimental study. MO conceived the thermal maturity calculation. All authors read and approved the final manuscript.

\section{Competing interests}

The authors declare that they have no competing interests.

\section{Publisher's Note}

Springer Nature remains neutral with regard to jurisdictional claims in published maps and institutional affiliations.

\section{Author details}

'Geological Survey of Japan, AIST, AIST Tsukuba Central 7, Higashi-1-1-1, Tsukuba, Ibaraki Pref. 305-8567, Japan. ²Earthquake Research Institute, University of Tokyo, 1-1-1 Yayoi, Bunkyo-ku, Tokyo 113-0032, Japan. ${ }^{3}$ Kochi
Institute for Core Sample Research, Japan Agency for Marine-Earth Science and Technology, 200 Monobe Otsu, Nankoku City, Kochi 783-8502, Japan.

Received: 30 March 2018 Accepted: 16 December 2018

Published online: 28 January 2019

\section{References}

Bangs NL, Shipley TH, Gulick SP, Moore GF, Kuromoto S, Nakamura Y (2004) Evolution of the Nankai Trough décollement from the trench into the seismogenic zone: inferences from three-dimensional seismic reflection imaging. Geology 32:273-276

Barr TD, Dahlen FA (1989) Brittle frictional mountain building: 2. Thermal structure and heat budget. J Geophys Res Solid Earth 94(B4):3923-3947

Barr TD, Dahlen FA, McPhail DC (1991) Brittle frictional mountain building 3. Lowgrade metamorphism. J Geophys Res Solid Earth 96(B6):10319-10338

Beaumont C, Ellis S, Pfiffner A (1999) Dynamics of sediment subductionaccretion at convergent margins: short-term modes, long-term deformation, and tectonic implications. J Geophys Res Solid Earth 104(B8):17573-17601

Beyssac O, Simoes M, Avouac JP, Farley KA, Chen YG, Chan YC, Goffé B (2007) Late Cenozoic metamorphic evolution and exhumation of Taiwan. Tectonics 26(6)

Burbidge DR, Braun J (2002) Numerical models of the evolution of accretionary wedges and fold-and-thrust belts using the distinct-element method. Geophys J Int 148(3):542-561

Chen WS, Chung SL, Chou HY, Zugeerbai Z, Shao WY, Lee YH (2017) A reinterpretation of the metamorphic Yuli belt: evidence for a middle-late Miocene accretionary prism in eastern Taiwan. Tectonics 36(2):188-206

Cundall PA, Strack OD (1979) A discrete numerical model for granular assemblies. Geotechnique 29:47-65

Fukuchi R, Yamaguchi A, Yamamoto Y, Ashi J (2017) Paleothermal structure of the Nankai inner accretionary wedge estimated from vitrinite reflectance of cuttings. Geochem Geophys Geosyst 18:3185-3196

Gerya T, Stöckhert B (2006) Two-dimensional numerical modeling of tectonic and metamorphic histories at active continental margins. Int J of Earth Sci 95: $250-274$

Gutscher MA, Kukowski N, Malavieille J, Lallemand S (1998) Episodic imbricate thrusting and underthrusting: analog experiments and mechanical analysis applied to the Alaskan accretionary wedge. J Geophys Res Solid Earth 103(B5):10161-10176

Harris R, Yamano M, Kinoshita M, Spinelli G, Hamamoto H, Ashi J (2013) A synthesis of heat flow determinations and thermal modeling along the Nankai Trough, Japan. J of Geophys Res Solid Earth 118:2687-2702

Hyndman RD, Wang K (1993) Thermal constraints on the zone of major thrust earthquake failure: the Cascadia subduction zone. J of Geophys Res Solid Earth 98:2039-2060

Jehlička J, Urban O, Pokorný J (2003) Raman spectroscopy of carbon and solid bitumens in sedimentary and metamorphic rocks. Spectrochim Acta A Mol Biomol Spectrosc 59(10):2341-2352

Kitamura Y, Sato K, Ikesawa E, Ikehara-Ohmori K, Kimura G, Kondo H, Ujie K, Onishi CT, Kawabata K, Hashimoto Y, Masago H, Mukoyoshi H (2005) Mélange and its seismogenic roof décollement: a plate boundary fault rock in the subduction zone-an example from the Shimanto Belt, Japan. Tectonics 24:TC5012. https://doi.org/10.1029/2004TC001635

Konstantinovskaia E, Malavieille J (2005) Erosion and exhumation in accretionan orogens: experimental and geological approaches. Geochem Geophys Geosyst 6(2)

Kukowski N, Von Huene R, Malavieille J, Lallemand SE (1994) Sediment accretion against a buttress beneath the Peruvian continental margin at $12 \mathrm{~S}$ as simulated with sandbox modeling. Geol Rundsch 83(4):822-831

Miyakawa A, Yamada Y, Matsuoka T (2010) Effect of increased shear stress along a plate boundary fault on the formation of an out-of-sequence thrust and a break in surface slope within an accretionary wedge, based on numerical simulations. Tectonophysics 484:127-138

Miyakawa A, Yamada Y, Otsubo M (2016) Stress changes in an accretionary wedge related to the displacement of an out-of-sequence thrust in a numerical simulation. Island Arc 25:433-435

Morgan JK (2015) Effects of cohesion on the structural and mechanical evolution of fold and thrust belts and contractional wedges: discrete element simulations. J Geophys Res Solid Earth 120(5):3870-3896

Mulugeta G, Koyi H (1992) Episodic accretion and strain partitioning in a model sand wedge. Tectonophysics 202:319-333 
Naylor M, Sinclair HD (2007) Punctuated thrust deformation in the context of doubly vergent thrust wedges: implications for the localization of uplift and exhumation. Geology 35:559-562

Sakaguchi A (1996) High paleogeothermal gradient with ridge subduction beneath the Cretaceous Shimanto accretionary prism, southwest Japan. Geology 24:795-798

Seno T, Stein S, Gripp AE (1993) A model for the motion of the Philippine Sea plate consistent with NUVEL-1 and geological data. J of Geophys Res Solid Earth 98:17941-17948

Stockmal GS, Beaumont C, Nguyen M, Lee B (2007) Mechanics of thin-skinned fold-and-thrust belts: insights from numerical models. Geol Soc Am Spec Pap 433:63-98

Suzuki N, Matsubayashi H, Waples DW (1993) A simpler kinetic model of vitrinite reflectance. AAPG Bull 77:1502-1508

Sweeney JJ, Burnham AK (1990) Evaluation of a simple model of vitrinite reflectance based on chemical kinetics (1). AAPG Bull 74:1559-1570

Underwood MB, Hibbard JP, DiTullio L (1993) Geologic summary and conceptual framework for the study of thermal maturity within the Eocene-Miocene Shimanto Belt, Shikoku, Japan. Geo Soc of Am Special Papers 273:1-24

Underwood MB, Laughland MM, Byrne T, Hibbard JP, DiTullio L (1992) Thermal evolution of the Tertiary Shimanto Belt, Muroto Peninsula, Shikoku, Japan. Island Arc 1:116-132

Underwood, MB, Laughland, MM, Wiley, TJ, and Howell, DG, Thermal maturity and organic geochemistry of the Kandik basin region, east-central Alaska, US Geological Survey, open file report OFR 89-353, 1989, 41 p.

Wenk L, Huhn K (2013) The influence of an embedded viscoelastic-plastic layer on kinematics and mass transport pattern within accretionary wedges. Tectonophysics 608:653-666

Willett S, Beaumont C, Fullsack P (1993) Mechanical model for the tectonics of doubly vergent compressional orogens. Geology 21(4):371-374

Yamada Y, Baba K, Matsuoka T (2006) Analogue and numerical modeling of accretionary prisms with a décollement in sediments. Geol Soc Lond, Spec Publ 253:169-183

Yamada Y, Baba K, Miyakawa A, Matsuoka T (2014) Granular experiments of thrust wedges: insights relevant to methane hydrate exploration at the Nankai accretionary prism. Mar Pet Geol 51:34-48

Yamamoto Y (2006) Systematic variation of shear-induced physical properties and fabrics in the Miura-Boso accretionary prism: the earliest processes during off-scraping. Earth Planet Sci Lett 244:270-284

Yamamoto Y, Hamada Y, Kamiya N, Ojima T, Chiyonobu S, Saito S (2017) Geothermal structure of the Miura-Boso plate subduction margin, central Japan. Tectonophysics 710:81-87

\section{Submit your manuscript to a SpringerOpen ${ }^{\circ}$ journal and benefit from:}

- Convenient online submission

- Rigorous peer review

- Open access: articles freely available online

- High visibility within the field

- Retaining the copyright to your article

Submit your next manuscript at $\boldsymbol{\nabla}$ springeropen.com 